entrevista] voLume 10 | NÚMERO 21 | MAIO 2017

[EDUARDO MOTTA]

Bacharel em Artes Visuais; consultor; editor de moda e diretor criativo e de

conteúdo da Radar - Inteligência e Projetos de Moda.

E-mail: eduardomotta@radarconsultoria.com

\title{
Histórias rendadas: entrevista com Fernanda Yamamoto
}

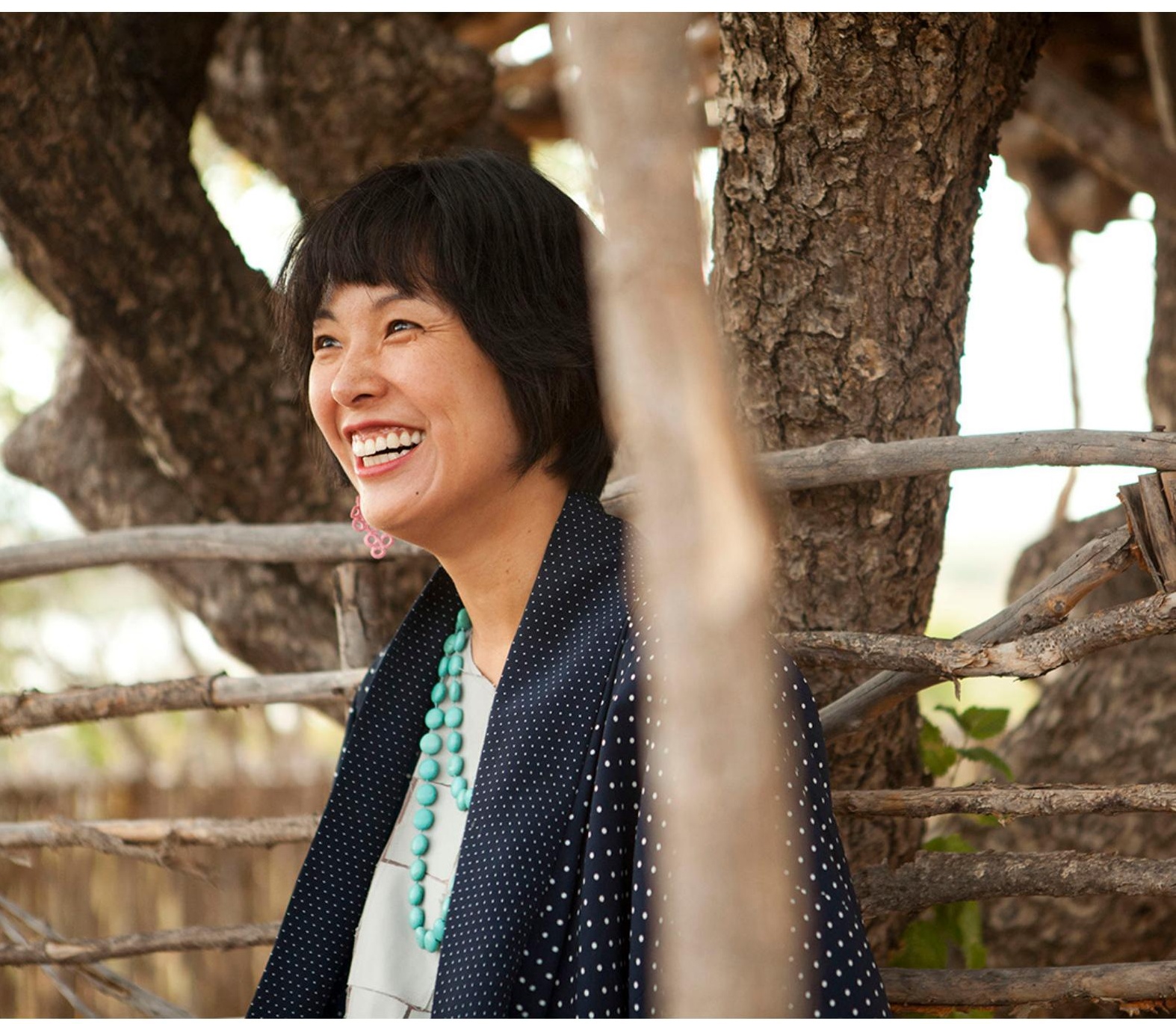

Figura 1: Fernanda Yamamoto por André Seiti. 
Desde que surgiu para a cena, Fernanda Yamamoto ganhou relevância entre os criadores nacionais por sua capacidade de articular ideias transformadoras.

Diante das demandas previsíveis do circuito comercial, ela se manteve fiel a um programa identificado por processos singulares de pesquisa, pelo caráter experimental das formas e pela inventividade da execução.

Abordar o trabalho dela implica falar das relações entre a indústria da moda e 0 artesanato. Fernanda tem vários projetos nesse viés e tem se dedicado ao artesanato brasileiro com notável sensibilidade, não apenas à técnica, mas também às estruturas socioculturais e estéticas que sustentam cada modalidade.

0 que ela reivindica dessas investigações - na condição de autora que o campo da moda Ihe confere - não é o direito indiscriminado sobre cada técnica, mas ao coeficiente de invenção instaurado a partir do ponto em que a parceria com os artesãos e com a tradição é instalada. A investigação das possibilidades de contração e expansão de pontos da renda renascença, resultado de trabalho com as artesãs do Cariri paraibano' é um exemplo do acerto desse posicionamento.

A roupa que ela faz é desfilada apenas uma vez ao ano, é resultado de processos aprofundados e parece obedecer a um tempo próprio antes de se constituir como tal.

EM - Como vê o futuro para a moda executada com atenção às relações interpessoais e culturais dos envolvidos em cada projeto de coleção?

Vejo como essencial. A partir deste ano vamos investir mais em mostrar como a roupa é feita, como é a sua construção e que ela não sai pronta de uma máquina. Nesse sentido é que organizamos visitas guiadas ao ateliê. A ideia é abrir todo o processo e dar acesso às pessoas que o fazem. Cada membro da equipe fala do seu trabalho.

EM - Como é trabalhar com criação de roupa a partir de uma sensibilidade particular em um momento em que a moda é tão generalizadamente abordada como processo de adequação ao mercado?

Não vejo outro modo de criar porque foi o que acreditei desde o princípio e é dessa forma que construí e estabeleci a marca. Claro que vejo a criação da roupa dentro de um mercado. 0 que ficou claro com o tempo é que existem dois momentos no ateliê: o do desfile, em que criamos sem preocupações comerciais, com licença para experimentar, testar novos tecidos, novas formas, entender a construção da roupa e enxergar a moda como forma de expressão mais abrangente. Outro momento é o da coleção comercial, que vem do conhecimento de mercado e da consumidora.

EM - Você já colocou a questão do processo de construção poética e o tempo como pontos de partida de uma coleção. Como é lidar com temas tão abstratos na criação de roupas?

Mesmo com temas abstratos é tranquilo porque sempre busco traduzir esses temas em pontos de partida concretos para dar o norte para a criação. 0 tema em si, a partir de certo ponto do processo criativo, tem papel secundário, deixamos que os caminhos apareçam naturalmente, sem ficarmos presos aos temas iniciais no decorrer do processo. No início, eles são fundamentais, mas vão se diluindo e ganhando novos contornos.

EM - Com quais questões está trabalhando no momento?

Estamos desdobrando a pesquisa que fizemos na Paraiba com renda renascença e iniciamos uma pesquisa com renda labirinto, que é um processo de destramar o tecido para depois tecer. Estive na comunidade japonesa Yuba, no 
interior de São Paulo. Na filosofia deles, as artes e os trabalhos na roça são igualmente importantes. Eles intercambiam a dureza e a leveza de um e de outro. Tem a ver com o tempo, com coexistir em uma sociedade que divide todo o trabalho, $\mathrm{e}$ tem a ver com as minhas origens.

EM - Como nasceu o trabalho com as rendeiras do Cariri paraibano?

Já conhecia a renda renascença, mas digo que tive o primeiro contato com a renda de verdade em meados de 2014, quando estive lá. Nesse momento, conheci o que existia "por trás da renda" e todo o seu valor simbólico imensurável. Junto com Romero Sousa ${ }^{2}$, e com o apoio da Cunhã Coletivo Feminista ${ }^{3}$, visitamos as casas das artesãs, vimos como a renda era feita, em qual ambiente e condições. Fizemos uma imersão no Cariri.

EM - Há momentos dessa coleção em que o grid lógico da renda é desconstruído e trazido para o universo das formas orgânicas, tão recorrentes no seu trabalho.

Uma percepção, desde o início - e eu acho que a primeira intuição é importantíssima no processo -, era de que a renda era rígida demais. Ela é sempre engomada, os pontos são miúdos, apertados, e os desenhos florais davam um ar "vovó". Consequentemente, é uma renda que demora para ser feita. 0 objetivo era trazer leveza, que a renda fosse feita com mais rapidez e com os desenhos abstratos característicos da marca. Também não usamos goma, o que tirou a tensão.

EM - Foram usados fios tradicionais ou foram introduzidos novos?

$\mathrm{Na}$ coleção Histórias Rendadas ${ }^{4}$ foram usados exatamente os materiais originais: linha de algodão e lacê de algodão. No último desfile, testamos a renda renascença com outros materiais, lacê de couro e um fio encerado.

\section{EM - Quantos artesãos estiveram envolvidos nesse projeto?}

Foram 77 artesãs, mulheres do Cariri paraibano, região que tem uma topografia particular. Os vilarejos e municípios são distantes uns dos outros e o deslocamento entre eles é difícil. É a região mais seca do Brasil. As artesãs, em sua grande maioria, dividem-se em associações e aprenderam a renda renascença com as mães, em média com 10 anos de idade. São mais velhas, muitas jovens não querem mais fazer. A renda está inserida em sua rotina. São agricultoras familiares, cuidam dos filhos, do marido, fazem bicos e fazem a renda nos intervalos de suas atividades.

\section{EM - 0 que representou a experiência com essas mulheres?}

Foi um divisor de águas, pessoal e profissional. A partir desse trabalho, desvelei um Brasil que pouco conhecia, comecei a enxergar de outra forma o artesanato, a relevância que um trabalho com moda pode ter. Fiquei muito tocada com as histórias e a situação daquelas mulheres. Convivo com um questionamento constante: o que fica para essas mulheres? 0 trabalho que fizemos foi uma gota d'água em um oceano, deu visibilidade para elas e para a renda, mas o que efetivamente mudou? Qual é o nosso papel como designer? Estas e tantas outras questões complexas ficam sem resposta e provocam um sentimento de impotência.

EM - Que cuidados tomar para que projetos que incorporam artesanato cumpram seus objetivos de gerar renda para comunidades de artesãos e respeitem 0 patrimônio que lhes pertence? 
Acho que respeitar o tempo deles, pensar em projetos de longo prazo e remuneração justa. É algo bem complexo: como remunerar? 0 que é o justo? Tivemos várias conversas com o coletivo Cunhã para chegar a um valor de remuneração. 0 fundamental é entender o contexto, compreender a realidade antes de intervir. Além disso, não pode ser uma relação vertical. No processo, é preciso respeitar a tradição, respeitar o tempo do artesão e sua bagagem cultural.

\section{EM - Por que processos colaborativos de criação?}

Porque acho fundamental. Na verdade, o meu trabalho é guiar uma rede de colaboradores. Dar direção e entender as potencialidades de cada um para chegar à criação com o conhecimento de todos.

EM - Como vê a questão de escala para um criador autoral?

É sempre um desafio fabricar um produto complexo em pequena escala. Mas, atrelado a isso, existe um processo do pequeno que é particular e que valoriza o produto. Os pequenos devem mostrar o que não se encontra nos grandes.

\section{EM - Qual o tamanho ideal para a marca Fernanda Yamamoto?}

Tamanho no qual possa continuar a fazer aquilo que acredito, e acompanhar de perto não só a criação, mas todo o processo de maneira horizontal. Não quero me tornar vertical na medida em que não enxergo o que está na base.

\section{EM - Tem algum projeto em particular que gostaria de realizar um dia?}

Meu sonho (e um plano futuro) é ter uma loja integrada ao ateliê, como são hoje os restaurantes nos quais você vê a cozinha aberta. As visitas guiadas surgiram da impossibilidade imediata de fazer isso.

\section{EM - Por que moda?}

Não sei. A moda tem um poder enorme de comunicar, tocar, transmitir mensagens, trazer questões tão pertinentes aos dias de hoje. A roupa é algo poderosissimo, abraça nosso corpo, nos dá personalidade.

\section{NOTAS}

10 trabalho rendeu a coleção Histórias Rendadas, apresentada em 2015, na SPFW.

${ }^{2}$ Professor concursado de Artes do Estado da Paraiba e do município de João Pessoa. Formado em licenciatura plena em Artes pela Universidade Federal da Paraiba, com especialização em Moda na área de Estilismo e Modelagem de Artefatos em Couro. Trabalha com criação de coleções, consultoria criativa, gestão em moda e confecção, produção e direção de arte em audiovisual.

${ }^{3}$ Organização social sem fins lucrativos, fundada em 1990, no Estado da Paraíba, nordeste do Brasil. Tem como missão promover a igualdade de gênero, tendo como referências a defesa dos direitos humanos, o feminismo, a justiça social e a democracia.

${ }^{4}$ Acesse o video para conhecer o trabalho no link: < www.fernandayamamoto.com.br/historiasrendadas> 